\title{
Growth, Structural and Optical Studies on Pure and Doped Magnesium Sulphate Heptahydrate Single Crystals
}

\author{
P. SUMITHRAJ PREMKUMAR ${ }^{1}$, \\ S. DAWN DHARMA ROY ${ }^{2}$ and X. SAHAYA SHAJAN ${ }^{1 *}$
}

${ }^{1}$ Centre for Scientific \& Applied Research, PSN College of Engineering and Technology, Melathediyoor, Tirunelveli - 627 152, Tamilnadu, India

${ }^{2}$ Department of Physics, Nesamony Memorial Christian College, Marthandum, Kanyakumari - 629 165, Tamilnadu, India

shajan89@gmail.com

Received 10 September 2013 / Accepted 6 October 2013

\begin{abstract}
Single crystals of pure and doped $\left(\mathrm{Cd}^{2+}, \mathrm{Hg}^{2+}\right.$ and histidine $)$ magnesium sulphate heptahydrate $\left(\mathrm{MgSO}_{4} .7 \mathrm{H}_{2} \mathrm{O}\right)$ crystals were grown by slow evaporation method. The entry of the dopants into the crystal lattice was confirmed by energy dispersive x-ray (EDX) analysis. The infrared spectra recorded for histidine doped magnesium sulphate crystals showed the presence of amino group in the grown crystal. The powder x-ray data was indexed and there was no significant lattice distortion was observed due to the addition of dopants. The thermograms recorded for the grown crystals showed that these crystals were thermally unstable and decompose through many stages. UV-Vis spectral studies showed that the crystals were transparent in the visible region.
\end{abstract}

Keywords: Magnesium sulphate heptahydrate, Crystal growth, Optical studies

\section{Introduction}

Crystallization of metal sulphate heptahydrate $\left(\mathrm{MSO}_{4} 7 \mathrm{H}_{2} \mathrm{O}\right)$ such as magnesium sulphate heptahydrate (MSHH), nickel sulphate heptahydrate (NSHH) and zinc sulphate heptahydrate (ZSHH) has become an important field of research for both academic interest and industrial applications in various areas like medical, agriculture and chemical industry ${ }^{1-3}$. These crystals are isomorphous to each other and they all belong to the orthorhombic system with space group $\mathrm{P} 2{ }_{1} \mathrm{P} 2{ }_{1} \mathrm{P} 2{ }_{1}$. They have tetra molecular unit cell and are important due to the availability of several hydrogen bonds.

The pure magnesium sulphate heptahydrate (MSHH) crystals have been grown at low temperature from aqueous solutions ${ }^{4-6}$. The presence of foreign particles in the growth media has long been recognized in changing the growth habits of crystals ${ }^{7-8}$. Jibbouri et al., presented the influence of difference additives $\left(\mathrm{KCl}, \mathrm{K}_{2} \mathrm{SO}_{4}, \mathrm{NaCl}\right.$ and $\left.\mathrm{MgCl}_{2}\right)$ on the crystallization kinetics of magnesium sulphate heptahydrate. They found that the impurities exert influence on the saturation and super-saturation limit. Ferdous et al., ${ }^{9}$ reported that the addition of $\mathrm{KCl}$ is found to increase the quality of the crystals. In the present study, we have attempted to grow pure and 
doped magnesium sulphate heptahydrate crystals by slow evaporation technique. The grown crystals are characterized by energy dispersive x-ray analysis, fourier transform infrared spectroscopy, powder $x$-ray diffraction, thermal studies (TG/DTA), UV-Vis spectroscopy. The results obtained are reported and discussed herein.

\section{Experimental}

Recrystallized samples of analytical reagent grade $\mathrm{MgSO}_{4} \cdot 7 \mathrm{H}_{2} \mathrm{O}$ and doubly distilled water were used in the present work for the growth of single crystals from aqueous solution by slow evaporation method. The pure crystals were grown by preparing a saturated solution of MSHH with water as solvent. The saturated concentration was kept same as reported by us earlier ${ }^{10}$. The solution is filtered and kept in a constant temperature bath (Sub-Zero make (acc. $= \pm 0.01^{\circ} \mathrm{C}$ ) at a predetermined temperature. Good quality and transparent crystals of MSHH were obtained in about 2-3 weeks time. The grown crystals were harvested and used for characterization studies. For the growth of doped crystals, $0.005 \mathrm{M}$ concentration of cadmium chloride, mercury chloride and histidine was added to the saturated pure solution of MSHH.

The entry of dopants into the crystal lattice was confirmed by energy dispersive x-ray (JEOL Model JED - 2300) analysis. The infrared spectrum of histidine doped MSHH was recorded using FT-IR spectrometer (JASCO with ATR facility). X-ray diffraction studies were carried out using powder x-ray diffractrometer (PANalytical make, ModelX'per PRO). The thermal stability of the grown crystals was studied using TGA and DTA (Perkin-Elmer thermogravimetric analyser) analysis. The experiment was done with a heating rate was $10{ }^{\circ} \mathrm{C} / \mathrm{min}$ in nitrogen environment. The optical studies of the grown crystals were carried out by UV Vis spectroscopy. The UV Vis spectra of the grown crystals were recorded using Shimadzu (Model UV - 1800) in the wavelength range $200-1200 \mathrm{~nm}$

\section{Result and Discussion}

\section{Energy dispersive spectral analysis}

The EDX spectra obtained for the $\mathrm{Cd}^{2+}$ and $\mathrm{Hg}^{2+}$ doped crystals are presented in Figures 1 and 2. From the spectra it is confirmed that the dopant has entered into the crystal lattice of MSHH. The characteristic peaks of cadmium $(3.133 \mathrm{keV})$ and mercury $(2.195 \mathrm{keV})$ are noted in the recorded EDAX spectrum.

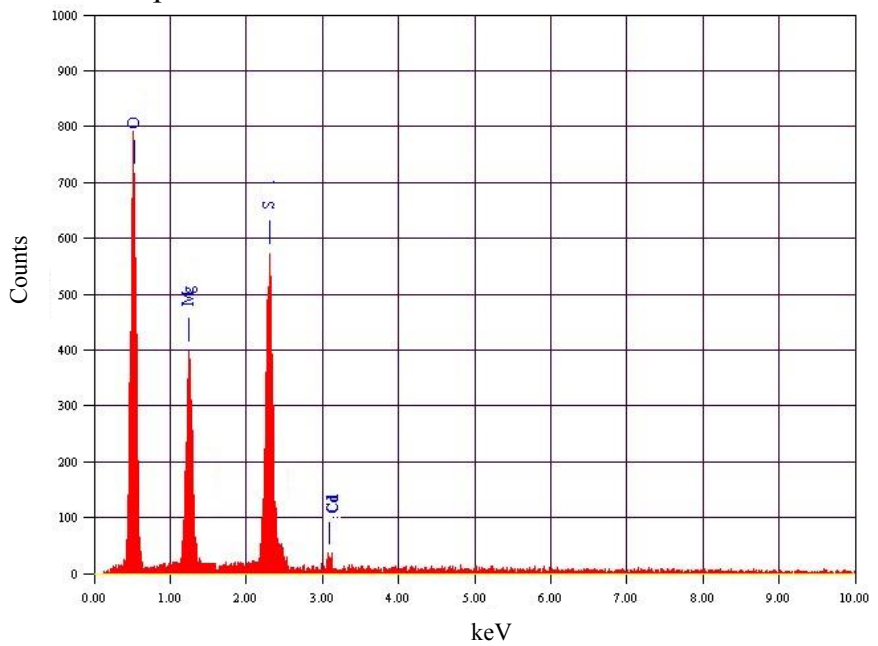

Figure 1. EDS spectrum of Cd doped MSHH 
The ionic radius of $\mathrm{Mg}^{2+}(0.72 \AA)$ is smaller than the ionic radius of both the dopants considered in the present study $\left(0.97 \AA\right.$ for $\mathrm{Cd}^{2+}$ and $1.02 \AA$ for $\left.\mathrm{Hg}^{2+}\right)$. Therefore it is expected the dopants may have entered into the crystal lattice as interstitials without affecting the overall charge neutrality of the crystal.

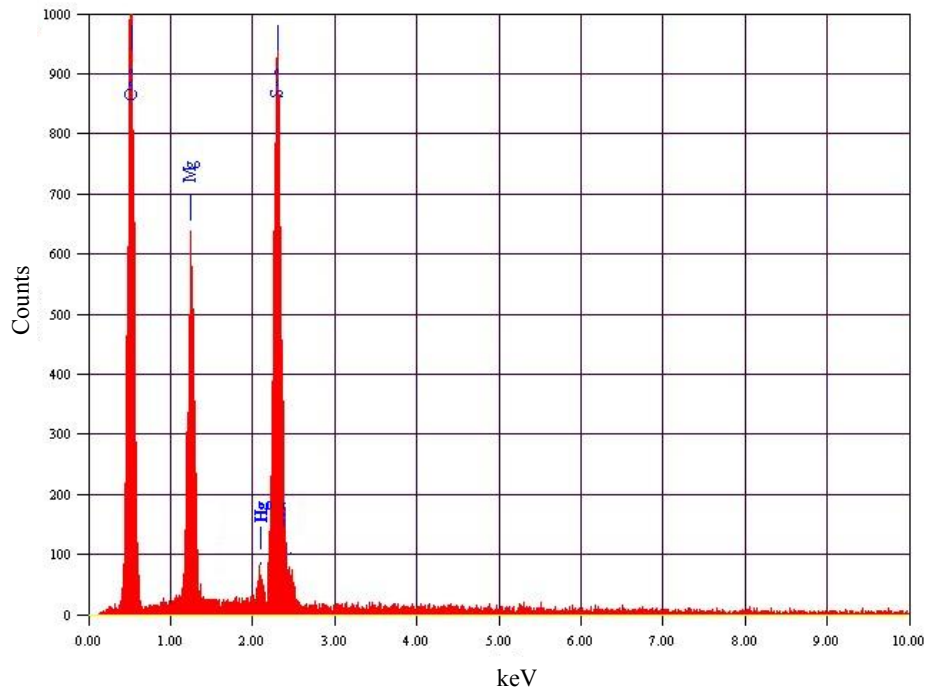

Figure 2. EDS spectrum of $\mathrm{Hg}$ doped $\mathrm{MSHH}$

\section{Fourier transform infra red spectral analysis}

The FT-IR spectra obtained for the $0.005 \mathrm{M}$ histidine doped MSHH crystals are shown in Figure 3. The observed absorption bands and their respective assignments are reported in Table 1.

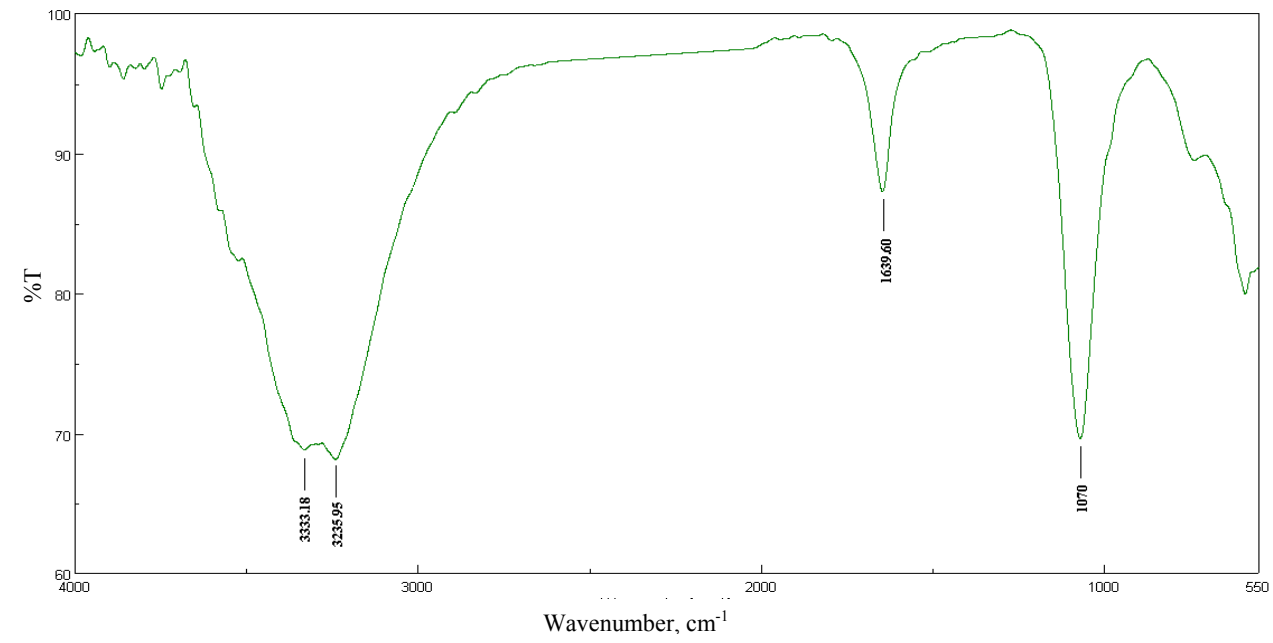

Figure 3. FTIR spectra of $0.005 \mathrm{M}$ histidine doped MSHH crystals

In the FT-IR spectrum of histidine doped magnesium sulphate heptahydrate single crystals, the broad band absorptions between $2779.99 \mathrm{~cm}^{-1}$ and $3652.26 \mathrm{~cm}^{-1}$ are due to $\mathrm{OH}$ stretching mode and water. The absorptions at $3333.18 \mathrm{~cm}^{-1}$ and $3235.95 \mathrm{~cm}^{-1}$ are due to $\mathrm{NH}$ 
stretching mode of primary amino group. The band at $1639.60 \mathrm{~cm}^{-1}$ is attributed to the $\mathrm{C}=\mathrm{O}$ stretch. The peak at $1070 \mathrm{~cm}^{-1}$ is due to $\mathrm{C}-\mathrm{N}$ stretch. The presence of amino group confirms the entry of histidine into the crystal lattice of MSHH.

Table 1. FTIR band assignment for histidine doped MSHH

\begin{tabular}{cc}
\hline Absorption Bands, in $\mathrm{cm}^{-1}$ & Band Assignment \\
\hline 3333.18 & N-H stretch \\
3235.95 & N-H symmetric stretches \\
1639.6 & C $=$ O stretch \\
1070 & C-N stretch \\
\hline
\end{tabular}

\section{$X$-ray diffraction analysis}

The x-ray diffraction pattern for the pure and doped MSHH crystals are presented in Figure 4. The x-ray diffraction agrees very well with the JCPDS data for pure MSHH [file No. 36 0419]. The indexed data of pure and doped crystals are tabulated in the Table 2. The X-ray diffraction pattern of the pure and doped MSHH single crystals differed in their relative intensities and the lattice spacing of the crystals. The reflection peaks are indexed with the help of powder X software ${ }^{11}$ and are tabulated.

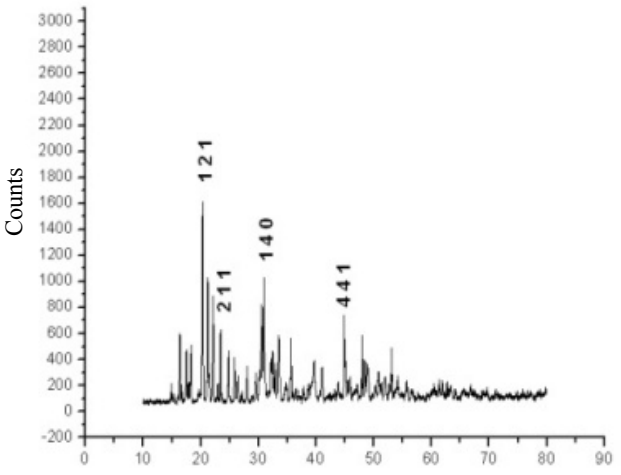

$2 \theta\left({ }^{\circ}\right)$

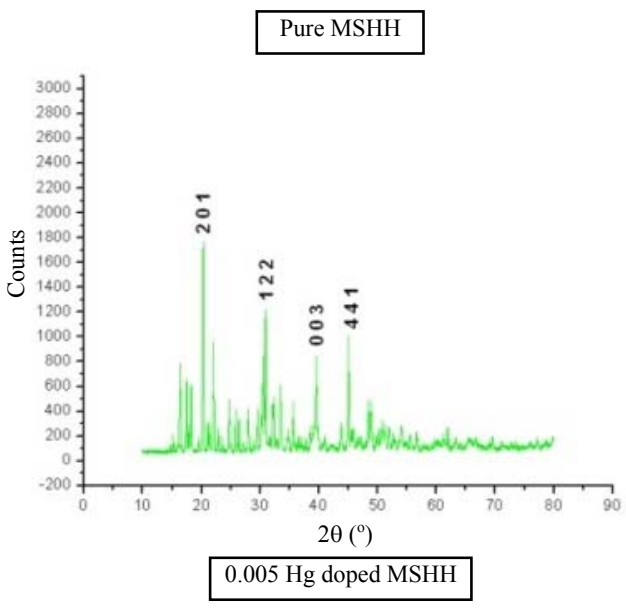

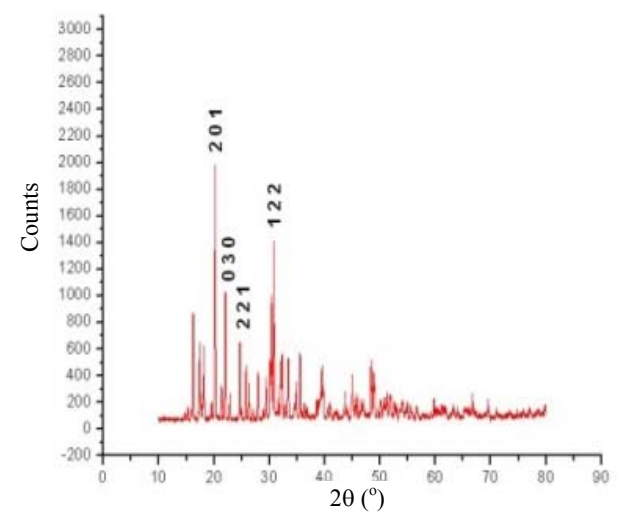

$0.005 \mathrm{Cd}$ doped $\mathrm{MSHH}$

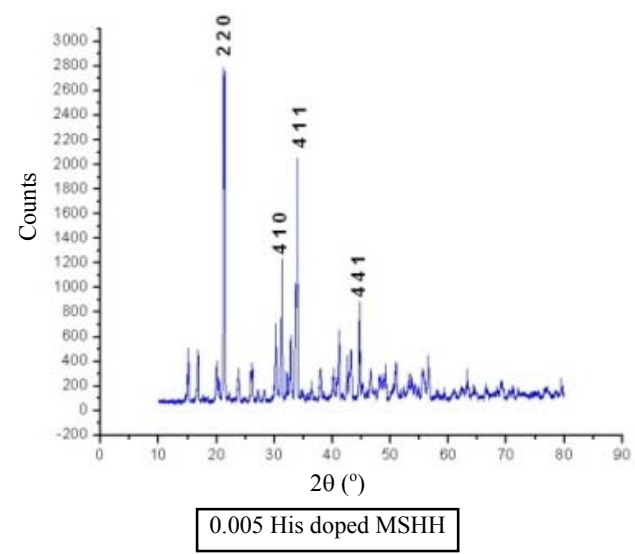

Figure 4. X-ray diffraction pattern of pure and doped MSHH 
Table 2. Indexed powder diffraction data for pure doped MSHH

\begin{tabular}{|c|c|c|c|c|c|c|c|c|c|}
\hline \multirow{2}{*}{ Samples } & \multicolumn{5}{|c|}{ Calculated } & \multicolumn{3}{|c|}{ Experimental } & \multirow{2}{*}{$\Delta 2 \theta\left(^{\circ}\right)$} \\
\hline & $2 \theta\left(^{\circ}\right)$ & $\mathrm{d}(\AA)$ & & $\mathrm{kl}$ & & $2 \theta\left(^{\circ}\right)$ & $\mathrm{d}(\AA)$ & $\mathrm{I} / \mathrm{I}_{0} \%$ & \\
\hline \multirow{7}{*}{ 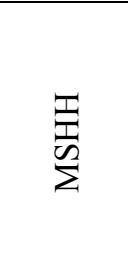 } & 21.084 & 4.2134 & 1 & 2 & 1 & 20.3688 & 4.3601 & 100 & 0.7152 \\
\hline & 21.165 & 4.1974 & 2 & 1 & 1 & 21.2401 & 4.1832 & 67.58 & -0.0751 \\
\hline & 22.274 & 3.9910 & 0 & 3 & 0 & 22.1287 & 4.0171 & 61.82 & 0.1453 \\
\hline & 30.161 & 2.9630 & 4 & 0 & 0 & 30.4821 & 2.9302 & 55.62 & -0.3211 \\
\hline & 30.809 & 2.9021 & 1 & 4 & 0 & 30.5734 & 2.9289 & 46.19 & 0.2356 \\
\hline & 31.009 & 2.8838 & 1 & 2 & 2 & 30.9397 & 2.8879 & 71.78 & 0.0693 \\
\hline & 45.038 & 2.0128 & 4 & 4 & 1 & 44.8387 & 2.0198 & 50.45 & 0.1993 \\
\hline \multirow{7}{*}{ 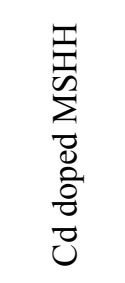 } & 16.590 & 5.3435 & 1 & 2 & 0 & 16.2915 & 5.4410 & 41.93 & 0.2985 \\
\hline & 16.692 & 5.3110 & 2 & 1 & 0 & 17.4177 & 5.0916 & 31.97 & -0.7257 \\
\hline & 19.808 & 4.4819 & 2 & 0 & 1 & 20.2270 & 4.3903 & 100 & -0.4190 \\
\hline & 22.274 & 3.9910 & 0 & 3 & 0 & 22.0229 & 4.0362 & 52.62 & 0.2511 \\
\hline & 24.815 & 3.5878 & 2 & 2 & 1 & 24.6812 & 3.6072 & 30.93 & 0.1338 \\
\hline & 30.161 & 2.9630 & 4 & 0 & 0 & 30.4083 & 2.9396 & 51.46 & -0.2473 \\
\hline & 31.009 & 2.8838 & 1 & 2 & 2 & 30.8240 & 2.9009 & 73.61 & 0.1850 \\
\hline \multirow{7}{*}{ 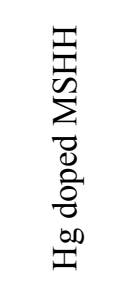 } & 16.590 & 5.3435 & 1 & 2 & 0 & 16.3770 & 5.4127 & 42.63 & 0.2130 \\
\hline & 19.808 & 4.4819 & 2 & 0 & 1 & 20.3247 & 4.3695 & 100 & -0.5167 \\
\hline & 22.274 & 3.9910 & 0 & 3 & 0 & 22.1220 & 4.0184 & 52.99 & 0.1520 \\
\hline & 30.809 & 2.9021 & 1 & 4 & 0 & 30.5256 & 2.9286 & 43.9 & 0.2834 \\
\hline & 31.009 & 2.8838 & 1 & 2 & 2 & 30.9035 & 2.8936 & 67.72 & 0.1055 \\
\hline & 39.457 & 2.2836 & 0 & 0 & 3 & 39.5321 & 2.2797 & 43.96 & -0.0751 \\
\hline & 45.038 & 2.0128 & 4 & 4 & 1 & 45.0192 & 2.0137 & 55.77 & 0.0188 \\
\hline \multirow{7}{*}{ 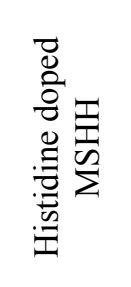 } & 21.094 & 4.2115 & 2 & 2 & 0 & 21.1787 & 4.1951 & 100 & -0.0847 \\
\hline & 21.165 & 4.1974 & 2 & 1 & 1 & 21.3957 & 4.1531 & 99.33 & -0.2307 \\
\hline & 31.093 & 2.8762 & 4 & 1 & 0 & 31.2497 & 2.8624 & 43.05 & -0.1567 \\
\hline & 33.726 & 2.6574 & 2 & 2 & 2 & 33.6637 & 2.6624 & 35.66 & 0.0623 \\
\hline & 33.798 & 2.6520 & 4 & 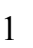 & 1 & 33.9187 & 2.6408 & 74.06 & -0.1207 \\
\hline & 34.504 & 2.5993 & 0 & 3 & 2 & 34.0159 & 2.6400 & 37.07 & 0.4881 \\
\hline & 45.038 & 2.0128 & 4 & 4 & 1 & 44.6365 & 2.0284 & 30.4 & 0.4015 \\
\hline
\end{tabular}

The difference in experimental $(2 \theta)$ and calculated $(2 \theta)$ values suggest that the structures are slightly distorted in comparison to the pure crystal. This may be due to the strain caused on the lattice of MSHH by the entry of dopants. For pure crystals, the deviation in $2 \theta$ values may be due to the presence of natural impurities in the solutions. Similar observations were reported in the literature?

\section{Thermal analysis}

The thermograms recorded for all the grown crystals and are presented in the Figures 5-8. The thermal stability of pure MSHH was not affected due to the addition of dopants. Two stages of decomposition are found while heating the crystals from ambient to $250{ }^{\circ} \mathrm{C}$. In both the stages of decomposition, water molecules are liberated. MSHH loses six water molecules at $176.42{ }^{\circ} \mathrm{C}$ whereas $\mathrm{Cd}, \mathrm{Hg}$ and histidine doped crystals loses six water molecules around $213.12{ }^{\circ} \mathrm{C}, 192.21{ }^{\circ} \mathrm{C}$ and $163.58{ }^{\circ} \mathrm{C}$ respectively. All the stages of decomposition are supported by the corresponding exothermic and endothermic dips observed in the DTA thermograms. The expected loss of molecules in each stages of decomposition and corresponding percentage weight loss are tabulated in Table 3 . There is a very good agreement between calculated and experimental weight loses. 


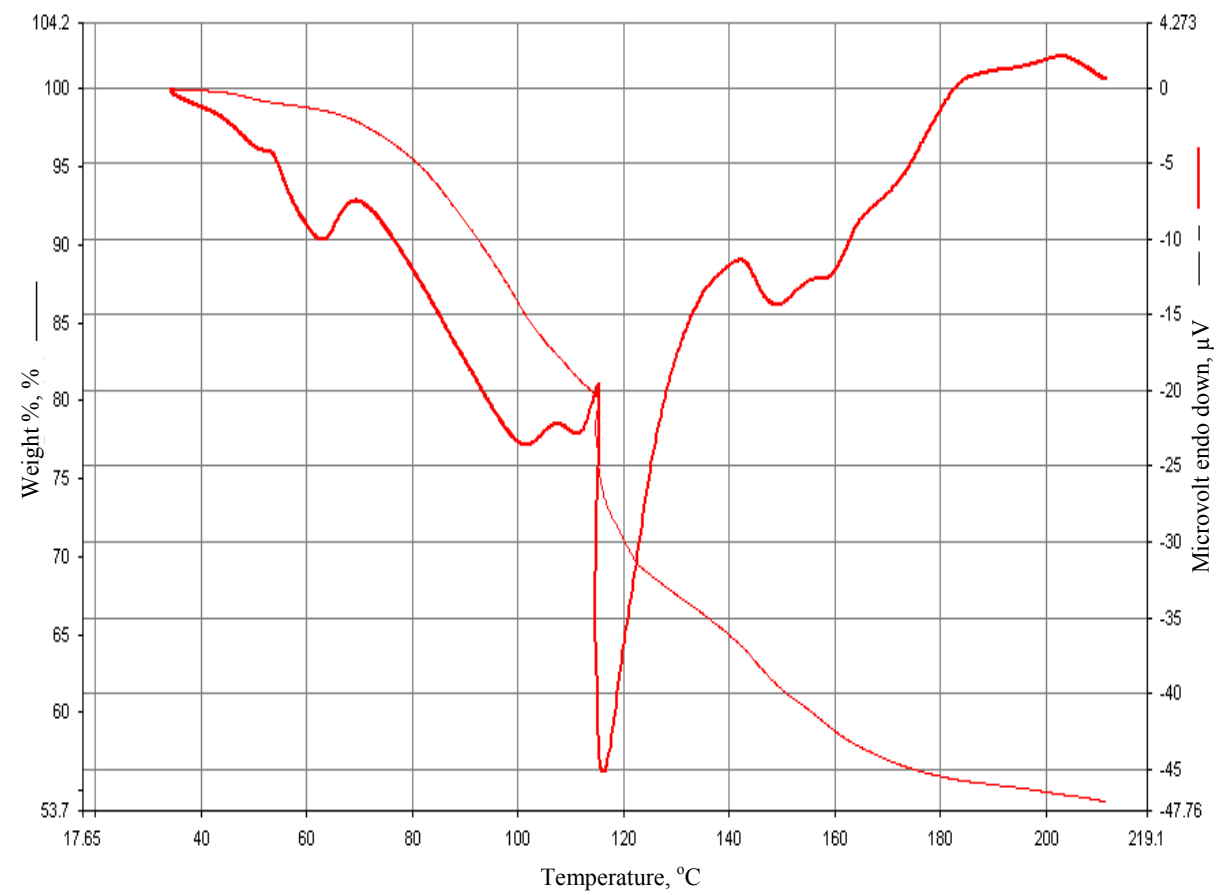

Figure 5. Thermogram of pure MSHH

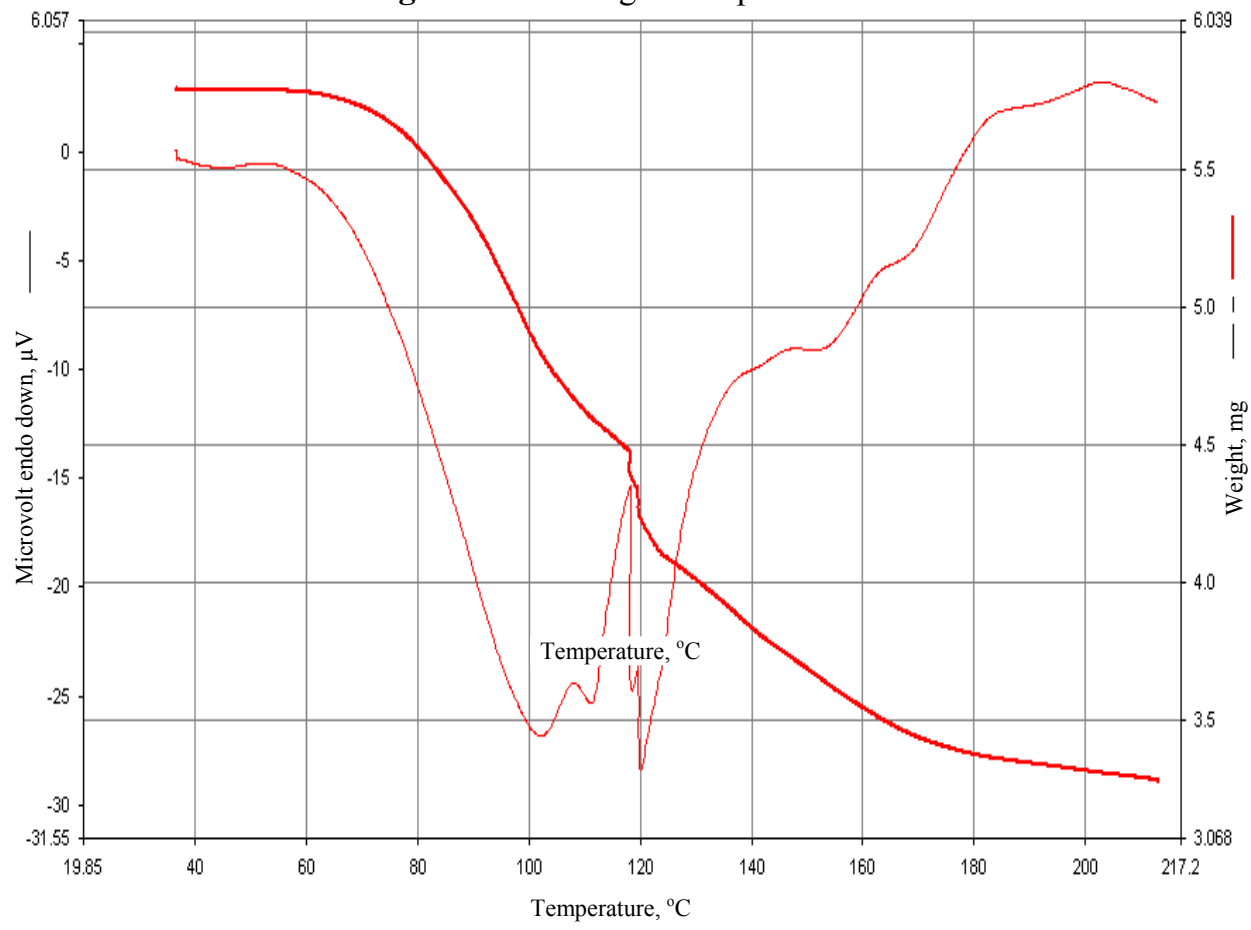

Figure 6. Thermogram of $\mathrm{Cd}$ doped $\mathrm{MSHH}$ 


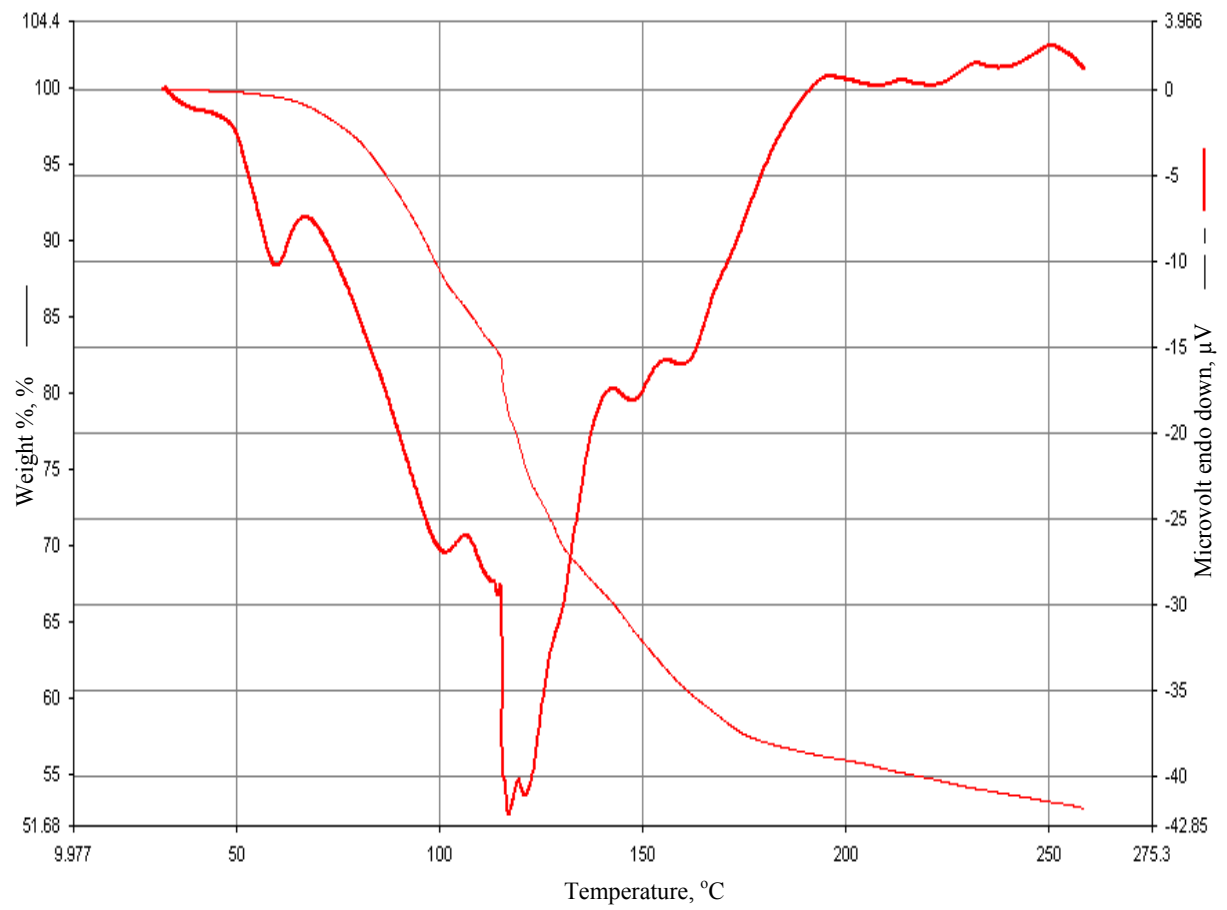

Figure 7. Thermogram of $\mathrm{Hg}$ doped MSHH

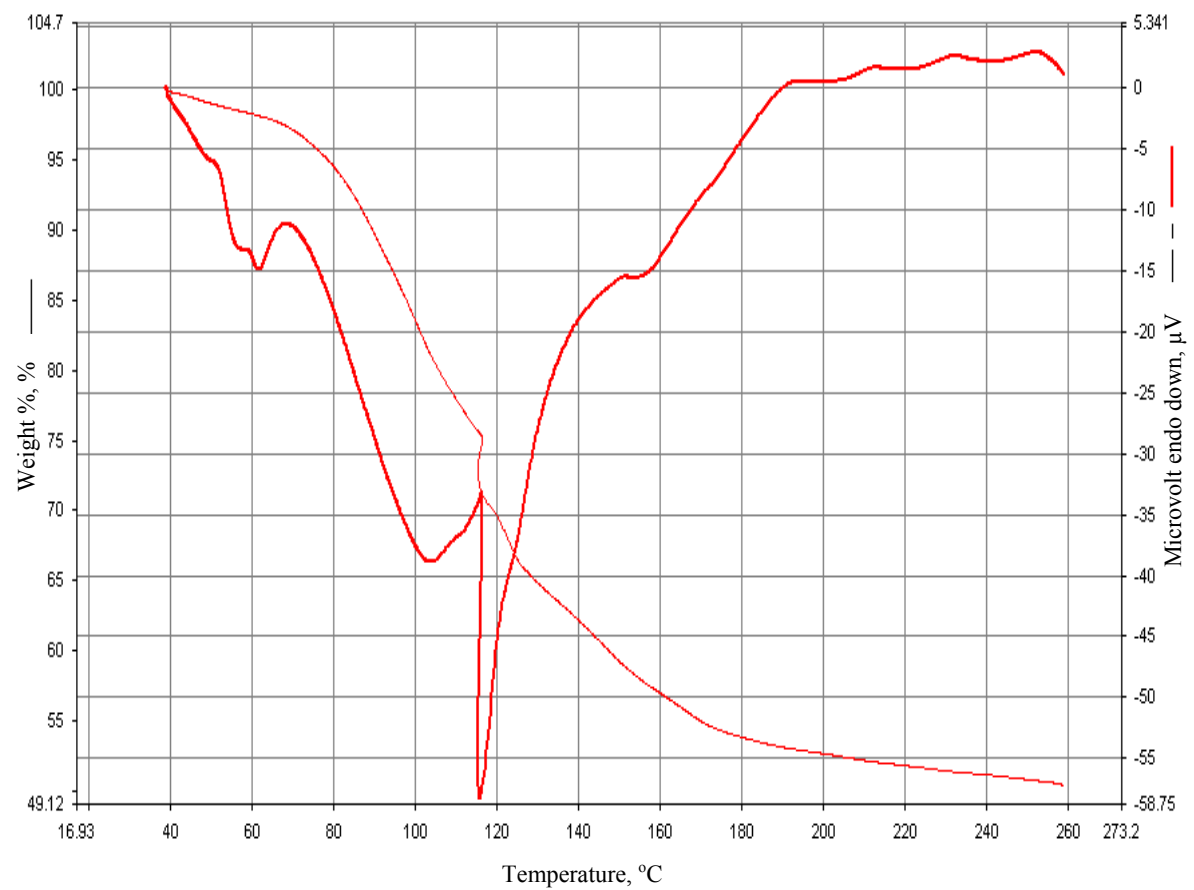

Figure 8. Thermogram of His doped MSHH 


\section{UV-Vis-NIR spectral analysis}

Single crystals are mainly used in optical applications and hence optical transmittance window and the transparency lower cut off (200-400 nm) is very important. This transparent nature in the visible region is a desirous property for the material used for NLO applications. The transmission spectra of pure and doped MSHH was recorded in the wavelength range between 200 and $1200 \mathrm{~nm}$. The UV-Vis spectra were presented in Figures 9-12. The pure and doped crystals have maximum transmission in the entire visible region. The lower cut off wavelength of pure, $0.005 \mathrm{M} \mathrm{Cd}, 0.005 \mathrm{M} \mathrm{Hg}$ and $0.005 \mathrm{M}$ histidine doped MSHH is $217.31 \mathrm{~nm}, 220.80 \mathrm{~nm}$, $221.68 \mathrm{~nm}$ and $245.19 \mathrm{~nm}$ respectively. The wide optical transmission window of the grown crystals shows that these crystals are potential candidates for optical applications.

Table 3. Percentage of weight loss in the different stages of decomposition of pure and doped MSHH

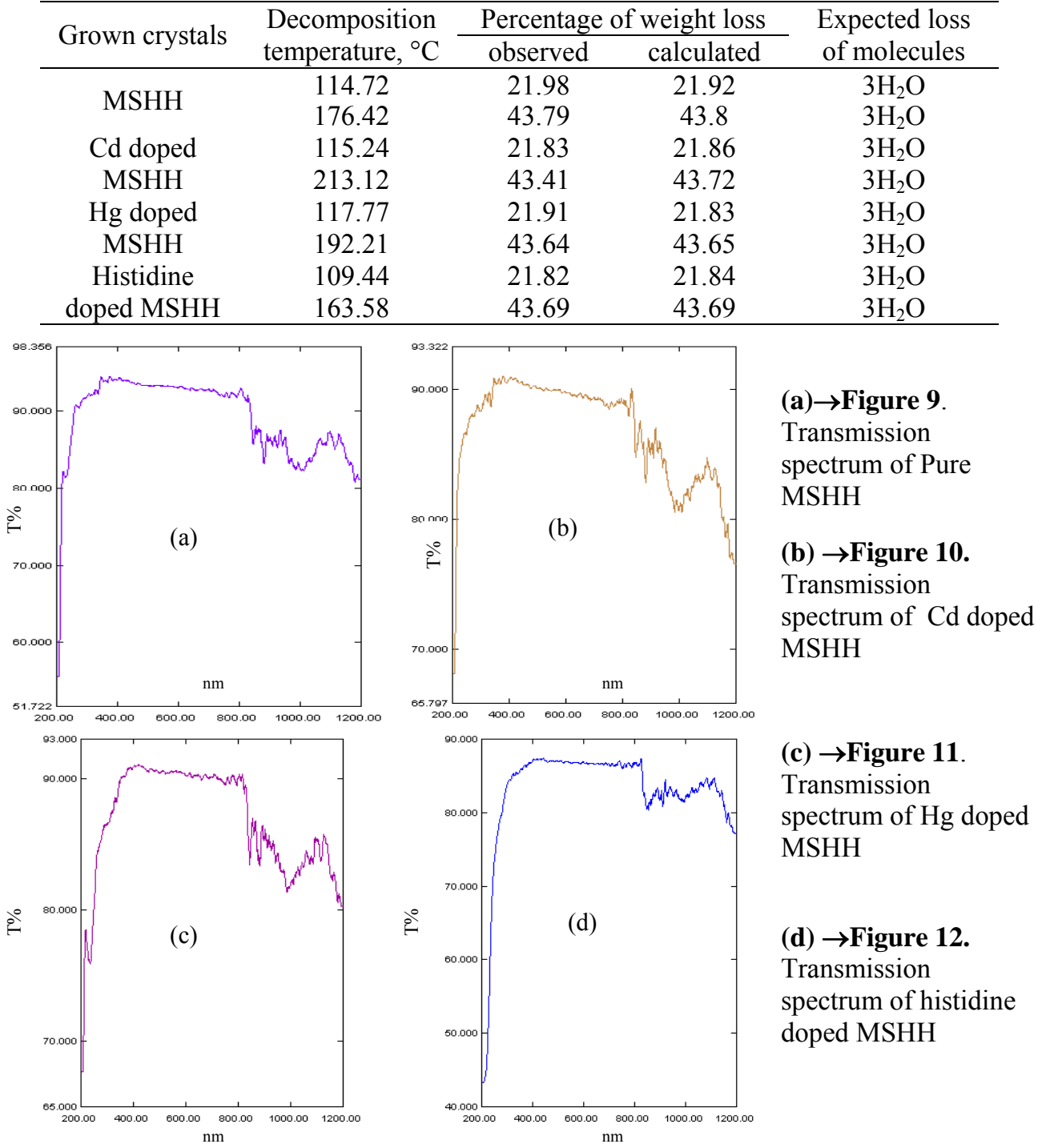




\section{Conclusion}

Pure and $0.005 \mathrm{M}$ doped $\left(\mathrm{Cd}^{2+}, \mathrm{Hg}^{2+}\right.$, histidine $)$ magnesium sulphate heptahydrate single crystals were grown by slow evaporation method. Energy dispersive x-ray spectroscopy and fourier transform infrared spectroscopy confirmed the presence of $\mathrm{Cd}, \mathrm{Hg}$ and histidine in the grown crystals. X-ray study reveals that the structures are slightly distorted due to the entry of dopants in to the crystal lattice. Enhancement of thermal stability was observed for the doped crystals. The crystals were found to decompose through two stages of decomposition. All the crystals possess a good transparency for the visible region which is essential for photonic devices.

\section{References}

1. Ikeya M, Hassan M G, Sasaoka H, Kinoshita Y, Takaki S and Yamanaka C, Appl Radiat Isot., 2000, 52(5), 1209-1215;

http://dx.doi.org/10.1016/S0969-8043(00)00073-7

2. Deminkaya S, Vural O, Gokail Z, Odabashi Z, Ozdag F, Erolu E and Yardim M, Norol Bil D, 1998, 15(3), 131-136.

3. Ema M, Gebrewold A, Altura B T and Altura B M, Report, Department of Physiology, State University of New York, Health Science Centre, Brooklyn, 1998.

4. Ramalingom S, Podder J and Kalkura S N, Cryst Res Technol., 2001, 36(12), 13571364; DOI:10.1002/1521-4079(200112)36:12<1357::AID-CRAT1357>3.0.CO;2-7

5. Kasatkin I A, Cryst Res Technol., 2002, 37(2-3), 193-206; DOI:10.1002/1521-4079(200202)37:2/3<193::AID-CRAT193>3.0.CO;2-5.

6. Sgualdino G, Vaccari G, Aquilano D and Rubbo M, J Cryst Growth, 1987, 83(4), 523-527; http://dx.doi.org/10.1016/0022-0248(87)90247-8

7. Jibbouri S A, Strege C and Ulrich J, J Cryst Growth, 2002, 236(1-3), 400-406; http://dx.doi.org/10.1016/S0022-0248(01)02172-8

8. Rubbo M, Aquilano D and Angela M F, J Cryst Growth, 1985, 71(3), 470-482; http://dx.doi.org/10.1016/0022-0248(85)90353-7

9. Ferdous S and Podder J, J Bang Acta Sci., 2009, 33, 47-54; DOI: $10.3329 /$ jbas.v33i1.2949

10. Sumithraj Premkumar P and Sahaya Shajan X, J Chem., 2010, 7S1, S121-126; http://dx.doi.org/10.1155/2010/518510

11. Dong C, J Appl Crysttallogr., 1999, 32(4), 838; DOI:10.1107/S0021889899003039. 